\title{
Numerical Simulation of the Growth and Removal of Inclusions in the Molten Steel of a Two-Strand Tundish
}

\author{
HAITAO LING ${ }^{1}$ and LIFENG ZHANG ${ }^{1,2}$ \\ 1.-School of Metallurgical and Ecological Engineering, University of Science and Technology \\ Beijing, Beijing 100083, People’s Republic of China. 2.—e-mail: zhanglifeng@ustb.edu.cn
}

In the current article, the growth of inclusions by turbulent collision and their removal in the molten steel of a two-strand tundish was calculated. The fluid flow was coupled with heat transfer and the concentration field of inclusions in the tundish. The weir and dam was effective to control the strong stirring energy within the inlet zone. The collision among inclusions in the inlet zone was far stronger than that in other zones. The rising velocity of $9.2-\mu \mathrm{m}$ inclusions was far smaller than the flow velocity; thus, small inclusions followed the fluid flow well. The concentration of $4-\mu \mathrm{m}, 5-\mu \mathrm{m}$, and $9.2-\mu \mathrm{m}$ inclusions at the outlet were $9.9 \mathrm{ppm}, 9.1 \mathrm{ppm}$, and $30.2 \mathrm{ppm}$, respectively. The concentration of other inclusions was within $2.0 \mathrm{ppm}-6.0 \mathrm{ppm}$. The total oxygen of the molten steel at the outlet after reaching the steady state was $38.5 \mathrm{ppm}$ assuming all inclusions were alumina. The removal fraction considering turbulent collision growth was $23.0 \%$ more than that without considering collision growth.

\section{INTRODUCTION}

To meet the demands for higher cleanliness of the steel, inclusions in the steel are always under strict control. $^{1-8}$ As an essential refining vessel, the continuous casting tundish shows markedly metallurgical functions for regulating the flow pattern of molten steel and inclusion removal. ${ }^{6,9-20}$ The generation and removal of inclusions in a practical tundish are the combination of multicomplicated physical and chemical processes. Nonmetallic inclusions mainly originate from reoxidation, slag entrainment, mechanical erosion of refractory, etc. The removal approaches of inclusions from the molten steel include collision and coalescence, flotation, and adhesion to solid surfaces including the bottom, side walls, and flow control devices of the tundish. When the gas purging operation is used in tundish, small bubbles are also in favor of the removal of inclusions. ${ }^{21,22}$

With special operational conditions, for instance, the high temperature, the visual opacity of molten steel, and the massive size of an industrial tundish, it is impossible to deeply understand and predict the mechanism of inclusion growth and removal in the tundish by actual operations. The numerical simulation is an alternative approach to predict the fluid flow pattern and inclusion transport in the tundish. Tacke and Ludwig ${ }^{9}$ investigated steel flow and inclusion removal by floating in a two-strand tundish, and they reported that the removal fraction of inclusions had an exponential increase relationship with the rising velocity. Their study was primarily focused on single-size inclusions and ignored the influence of temperature. Sinha and Sahai ${ }^{14}$ reported that the inclusion removal efficiency was biggest when weir, dam, and baffle were properly used in continuous casting tundish, and the removal fraction of, $25-\mu \mathrm{m}-40-\mu \mathrm{m}, \quad 45-\mu \mathrm{m}-72-\mu \mathrm{m}$, and $75-\mu \mathrm{m}-150-\mu \mathrm{m}$ inclusions were $83.1 \%, 84.0 \%$, and $91.7 \%$, respectively. Their study ignored the influence of the natural convection on fluid flow. In the actual operation, as heat loss exists, the effect of the thermal buoyancy in the tundish on the flow is extremely important. For the non-isothermal process, the fluid flow and the inclusion motion are quite different from that of the isothermal process. ${ }^{11-13,18,19}$ The current author, Zhang, studied the removal rate of different mechanisms in two regions separated by a weir in the tundish and comparing the calculation with industrial measurement. ${ }^{15}$ Zhang also studied the nucleation and growth of inclusions by diffusion, Brownian collision, Stokes collision, and turbulent collision by 
numerical simulation. ${ }^{23-26}$ However, in these studies, the effect of fluid flow on the agglomeration among inclusion particles was not considered, and the coalescence was only estimated from the average turbulent energy dissipation rate. To investigate the collision and growth mechanism of inclusions, it is of importance to combine these collision and growth mechanisms with the fluid flow to correctly simulate the removal of inclusions from the continuous casting tundish.

In the study, the flow field and temperature distribution in a two-strand tundish was calculated first under a non-isothermal condition, and then the growth and removal of inclusions and the local concentration of inclusions were simulated by combining the authors' user-defined subroutines with the commercial CFD software.

\section{MATHEMATICAL FORMULATION}

The molten steel in the tundish was assumed to be an incompressible Newtonian steady flow. The main governing equations for fluid flow and temperature distribution consist of the continuity equation, the Navier-Stokes equations, the turbulence energy, and its dissipation rate equations. The effect of natural convection on the fluid flow is considered by incorporating the Boussinesque's term $\left(\beta\left(T_{0}-T\right) \rho_{0} g_{i}\right)$ into the vertical direction of the momentum balance equation. The heat loss for each part of the tundish consisted of the fixed values shown in Table I.

The inclusions are assumed to be spherical alumina with the density of $5000 \mathrm{~kg} / \mathrm{m}^{3}$, and they are uniformly distributed in the molten steel at the initial time. The total volume fraction occupied by inclusions is so little that the effect of inclusions on fluid flow is negligible. The generation of inclusions in the tundish due to reoxidation, mechanical erosion of refractory, and slag entrainment is ignored. The effect of the fluctuation of free surface on fluid flow and inclusion transport is negligible.

The concentration of inclusions in the molten steel is given below:

$$
\frac{\partial\left(\rho n_{k}\right)}{\partial t}+\frac{\partial}{\partial x_{j}}\left(\rho u_{j} n_{k}\right)=\frac{\partial}{\partial x_{j}}\left(\Gamma \cdot \frac{\partial n_{k}}{\partial x_{j}}\right)+S_{k}
$$

Table I. The heat flux values for each part of the tundish $^{10}$

\begin{tabular}{lc}
\hline Parameters & Data $\left(\mathbf{k W} / \mathbf{m}^{\mathbf{2}}\right)$ \\
Heat flux at the top surface & 15 \\
Heat loss from the bottom wall & 1.4 \\
Heat loss from the long wall & 3.2 \\
Heat loss from the short wall & 3.8 \\
Heat loss from internal walls & 1.75 \\
(dam, weir, stopper rod) & \\
\hline
\end{tabular}

where the diffusion coefficient of the inclusion particles, $\Gamma$, is calculated by the effective viscosity $\mu_{\text {eff }}$ as: ${ }^{14}$

$$
\Gamma=\rho \cdot D_{\text {eff }}=\rho \cdot \frac{\mu_{\text {eff }}}{\rho}=\mu_{\text {eff }}
$$

where $n_{k}$ represents the number density of the inclusions composed of $k$-pieces of primary particles per unit volume; $u_{j}=\left(u_{1}, u_{2}, u_{3}-V_{k}\right)$ is the flow velocity of inclusion particles, and $u_{1}, u_{2}$, and $u_{3}$ are the liquid velocity in the tundish in the $x, y$ and $z$ directions, respectively, and $V_{k}$ is the terminal floating velocity of inclusion particles; $\rho$ is the density of steel; and $S_{k}$ is the source term for the inclusion transport including the generation term and the dissipation term.

For the inclusion particles with radius $r_{k}$, the terminal rising velocity, $V_{k}$, is described by the Stokes' law:

$$
V_{k}=\frac{2 g\left(\rho-\rho_{p}\right) \cdot r_{k}^{2}}{9 \mu}
$$

where $\rho_{p}$ is the density of the inclusion particle, $g$ is the acceleration of gravity, and $\mu$ is the viscosity of the fluid.

In practice, a large number of small-size inclusions enter the tundish with the incoming steel. During the residence time of molten steel in the tundish, inclusions collide with each other to form larger ones. ${ }^{15}$ There are several collision mechanisms. In most cases, Stokes collision exists under the laminar flow. Since the fluid flow in the tundish is always turbulent, Stokes collision among inclusion particles should be negligible. In the current article, the turbulent collision among inclusions is considered. Inclusions were assumed to be removed when floating up to the top surface.

Based on the Saffman and Turner's model ${ }^{27}$ and Higashitani's theory, ${ }^{28}$ the collision frequency, $N_{i j}$, per unit time and unit volume between two inclusions having radius $r_{i}$ and $r_{j}$ in molten steel is

$$
N_{i j}=1.3 \alpha \cdot\left(r_{i}+r_{j}\right)^{3} \cdot(\varepsilon / v)^{1 / 2} \cdot n_{i} \cdot n_{j}
$$

where $\varepsilon$ is the turbulent energy dissipation rate; $v$ is the kinematic viscosity of molten steel; $n_{i}$ and $n_{j}$ are the number density of particles with radius $r_{i}$ and $r_{j}$ per unit volume, respectively; and $\alpha$ is the agglomeration coefficient, correlated by the following approximate equation: ${ }^{29}$

$$
\alpha=0.727\left(\frac{\mu a_{1}^{3}(\varepsilon / v)^{1 / 2}}{A_{131}}\right)^{-0.242}
$$

where $a_{1}$ is the radius of the primary particle and $A_{131}$ is the effective Hamaker constant of particle 1 in medium 3. In the study, the effective Hamaker constant of alumina inclusions in molten steel was defined to be $A_{131}=2.3 \times 10^{-20} \mathrm{~J}^{30}$ 
The corrected population balance equation by Nakaoka is used to predict the size and concentration distribution of inclusions in the molten steel. Under the condition, $r_{k}^{3}=r_{k-i}^{3}+r_{i}^{3}$, and the corresponding equation is: ${ }^{29}$

$S_{k}=\frac{d n_{k}}{d t}=\frac{1}{2} \sum_{i=1, i+j=k}^{i=k-1}\left(1+\delta_{i j}\right) \cdot N_{i j}-\sum_{i=1}^{\infty}\left(1+\delta_{i k}\right) \cdot N_{i k}$

where $\delta_{i j}$ is the Kronecker's delta function and given below:

$$
\delta_{i j}= \begin{cases}1 & i=j \\ 0 & i \neq j\end{cases}
$$

The first term at the right-hand side of Eq. 6 represents the generation of the $k$ th-size inclusion with radius $r_{k}$ from the agglomeration of smaller particles, $r_{j}$ and $r_{k-j}$. The second term represents the disappearance from agglomeration into larger inclusions.

In the current study, the tundish is two-strand and with a capacity of $60 \mathrm{t}$. The parameters of tundish geometry, the calculated flow field, and temperature distribution are taken from Ref. 20. According to relevant studies, ${ }^{15,31-33}$ the smallest inclusions in Low-Carbon Al-Killed steel are approximately $1.0 \mu \mathrm{m}-4.0 \mu \mathrm{m}$. Thus, the initial radius of the primary inclusions is assumed to be $2.0 \mu \mathrm{m}$ in the current article. The entire particle size distribution is divided into 12 groups as shown in Table II.

The number density of the primary particles is $4.454 \times 10^{12} \# / \mathrm{m}^{3}$ at the initial time, and the corresponding total oxygen is $50 \mathrm{ppm}$.

(1) The boundary conditions for inclusions are as below: The number density of the primary particles is $4.454 \times 10^{12} \# / \mathrm{m}^{3}$ at the tundish inlet.

(2) The inclusion particles are assumed to be absorbed at the free surface by a flux of

Table II. The size distribution of inclusion particles

\begin{tabular}{lc}
\hline Group & Diameter $(\boldsymbol{\mu m})$ \\
1 & 4.0 \\
2 & 5.0 \\
3 & 5.8 \\
4 & 6.3 \\
5 & 6.8 \\
6 & 7.3 \\
7 & 7.7 \\
8 & 8.0 \\
9 & 8.3 \\
10 & 8.6 \\
11 & 8.9 \\
12 & 9.2 \\
\hline
\end{tabular}

$$
q_{k}=V_{k} \cdot C_{k},
$$

where $q_{k}$ is the particle flux density in the vertical direction at the free surface (number of particles leaving the surface per unit area and unit time); and $C_{k}$ is the number density of particles in the grid cell immediately adjacent to the surface.

(3) The removal of inclusions due to sticking to solid surfaces, such as the tundish bottom, side walls, and flow control device, is neglected. A no-flux condition for inclusions is assumed at the wall boundaries.

(4) Inclusions enter into the continuous casting together with the molten steel at the outlet with a flux of

$$
q_{o}=w \cdot C,
$$

where $w$ is the liquid velocity in the normal direction at the outlet and $C$ is the number density of inclusion particles at the outlet.

The loss flux due to collision and coalescence, flotation, and removal through the outlet of inclusions were computed by loading the authors' userdefined subroutines into the concentration equation of inclusions. The residuals of number density of all size inclusions were set to $10^{-5}$. The flowchart of the mathematical models is given in Fig. 1.

\section{FLUID FLOW IN THE TUNDISH}

Figure 2 shows the distribution of fluid flow velocity, streamline, and turbulent energy dissipation rate at the symmetrical plane of the tundish. The molten steel from the ladle shroud first impinges on the bottom of the tundish and then flows along the bottom. The molten steel flows toward the inlet zone by installing a weir and dam, and then two counter flows are formed beneath the inlet. At the same time, the molten steel flowing back to the inlet hits against the new incoming steel, so that their own flow velocities are greatly weakened. The velocity of the molten steel from the weir and dam is significantly less than that of the inlet zone. The strong stirring energy is effectively controlled within the inlet zone using the weir and dam, as shown in Fig. 2c. The turbulent energy dissipation rate in the inlet zone is larger than that of other zones in the tundish. Furthermore, it is well known that the turbulent energy dissipation rate is a key factor for collision and coalescence among inclusions. Thus, the collision and coalescence among inclusions in the inlet zone should be far stronger than that in other zones.

Figure $2 \mathrm{~b}$ also shows that the molten steel from the weir and dam flows upward and reaches the top surface. After impinging on the stopper rod, it flows downward to the middle height of the rod, which creates two big circulations. Moreover, part of the molten steel flows toward the outlet along the side wall. Most of the kinetic energy of the molten steel 


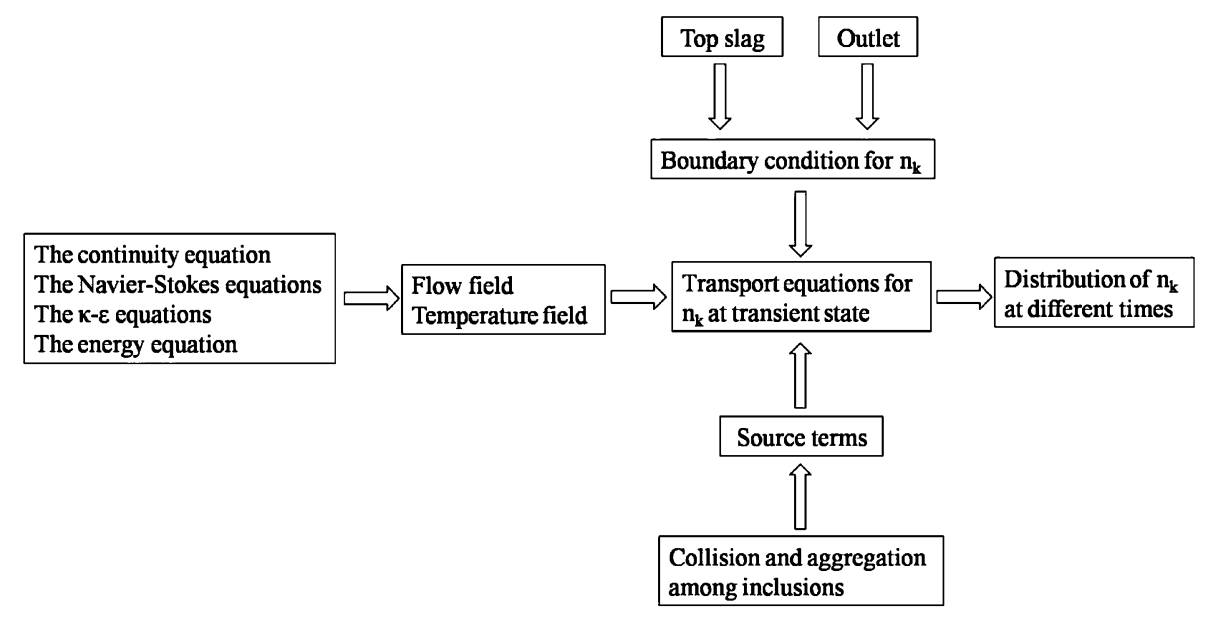

Fig. 1. Flowchart of the mathematical models.

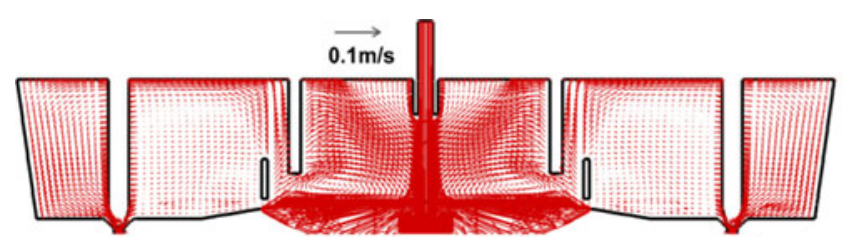

(a)

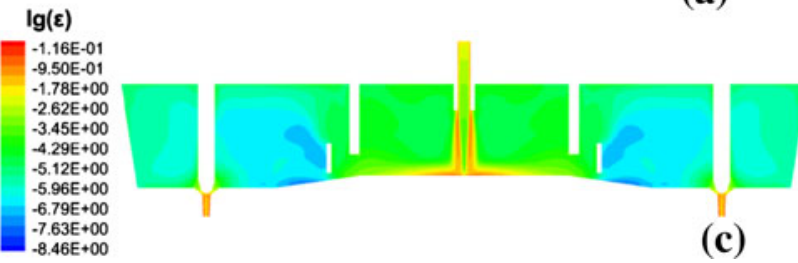

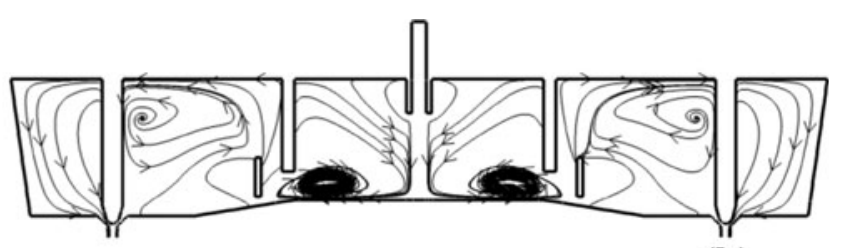

(b)

Fig. 2. Predicted distribution at the symmetry plane in the tundish of (a) velocity; (b) streamline; and (c) turbulent energy dissipation rate.

is dissipated in the inlet zone. Therefore, the molten steel from the weir and dam becomes smooth, which is very beneficial to the floating removal of inclusions in the tundish. In Fig. 2c, compared with other zones, the distribution of the turbulent energy dissipation rate behind the dam is the smallest and the collision and coalescence among inclusions should be much weaker.

\section{INCLUSION COLLISION AND REMOVAL IN THE TUNDISH}

Figures 3, 4, 5 and 6 show the distribution of the number density of inclusions of four different sizes at six different moments. At the beginning, the collision and coalescence among primary particles occurred in the entire zone of the tundish, as shown in Figs. 3 and 4. Meanwhile, the incoming steel from the ladle shroud contained a great number of primary particles, which moved together with the molten steel and agglomerated simultaneously. Figure $3 a$ shows that the number density of primary particles in the inlet zone was markedly less than that in other zones, which was due to the strong turbulence in the inlet zone promoting the collision and coalescence among primary particles. Thus, the primary inclusions continuously disappeared, and new bigger sized inclusions gradually formed. Furthermore, the number density of 5.0- $\mu \mathrm{m}$ inclusions in the inlet zone was greater than other zones. For the above two-sized inclusions, their number density showed an inverse distribution behind the dam because of the weak turbulence.

According to the previous analysis, inclusions had high collision frequency due to strong stirring energy in the inlet zone, and the dissipation of smallsized inclusions in the inlet zone was much higher than in other zones. The generation rate of largesized inclusions had a similar change tendency. When reaching the steady state $(1901.5 \mathrm{~s})$, the distribution of the number density of $5.0-\mu \mathrm{m}$ inclusions was very similar to that of a turbulent energy dissipation rate, showing a maximum value in the inlet zone and a minimum value behind the dam.

Figures 5 and 6 show that $8.9-\mu \mathrm{m}$ and $9.2-\mu \mathrm{m}$ inclusions started to generate at the bottom of the inlet zone at $11.5 \mathrm{~s}$, and the local strong turbulence favored the collision and coalescence of smaller 


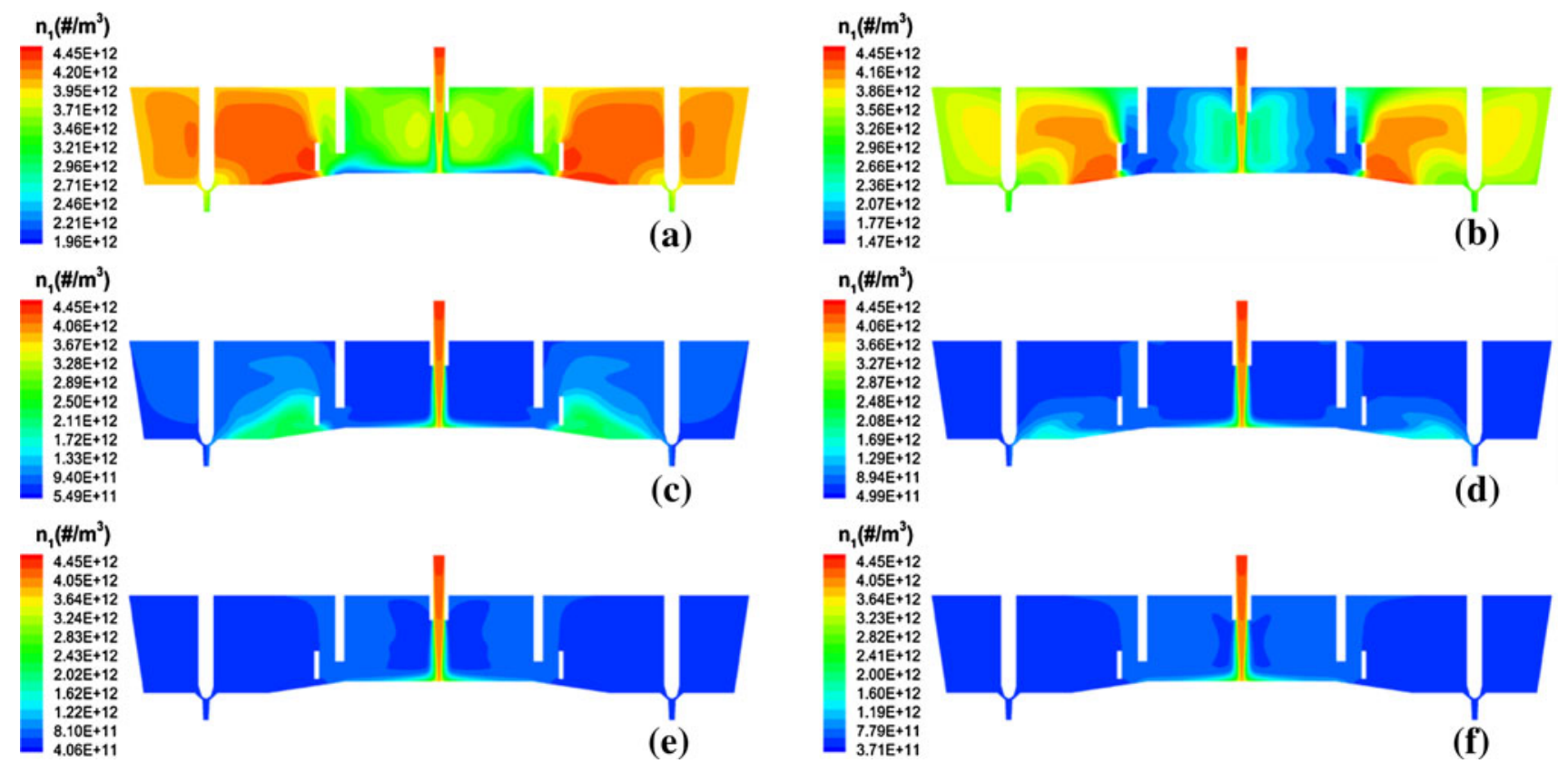

Fig. 3. The number density distribution of $4.0-\mu \mathrm{m}$ inclusions at different times: (a) $11.5 \mathrm{~s}$; (b) $31.5 \mathrm{~s}$; (c) $401.5 \mathrm{~s}$; (d) $601.5 \mathrm{~s}$; (e) $1201.5 \mathrm{~s}$; (f) $1901.5 \mathrm{~s}$.

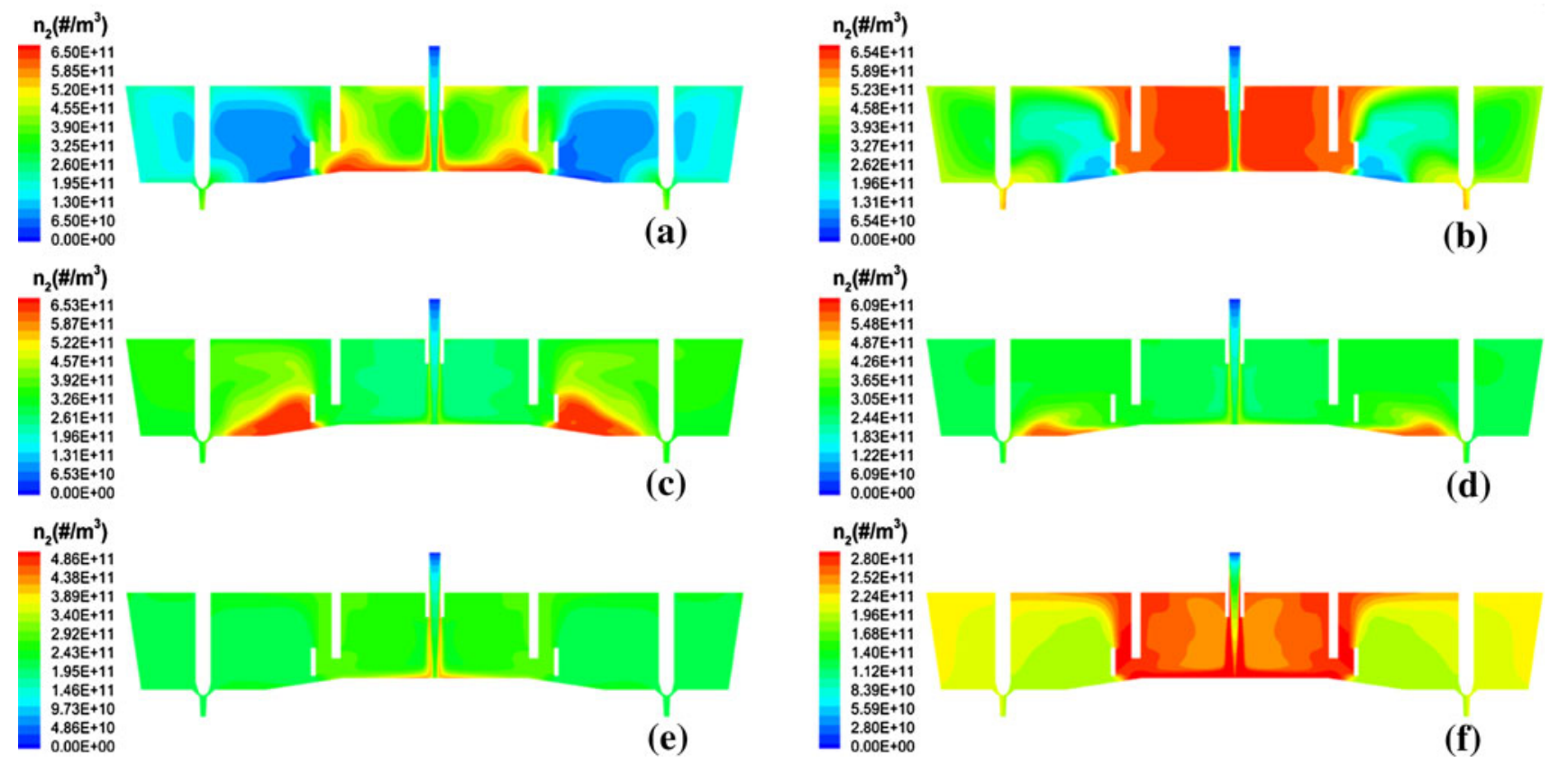

Fig. 4. The number density distribution of 5.0- $\mu \mathrm{m}$ inclusions at different times: (a) $11.5 \mathrm{~s}$; (b) $31.5 \mathrm{~s}$; (c) $401.5 \mathrm{~s}$; (d) $601.5 \mathrm{~s}$; (e) $1201.5 \mathrm{~s}$; (f) $1901.5 \mathrm{~s}$.

inclusions to form bigger ones. According to Eq. 3, the rising velocity of the largest size inclusions was $1.39 \times 10^{-5} \mathrm{~m} / \mathrm{s}$, far smaller than the fluid flow velocity. Thus, small inclusions followed the fluid flow well. Large-sized inclusions forming in the inlet zone moved toward the rear of the dam together with the molten steel. At $1201.5 \mathrm{~s}$ and $1901.5 \mathrm{~s}$, the number density of $8.9-\mu \mathrm{m}$ and $9.2-\mu \mathrm{m}$ inclusions behind the dam was greater than that in the inlet zone (Figs. 5 and 6 ).

During the transient calculation, the monitoring curves of the inclusion number density were obtained to determine the equilibrium state. In the study, the position of the monitoring point is at (2.0, 0, 0.7955), and Fig. 7 shows the variation of inclusion number density for three different groups with 


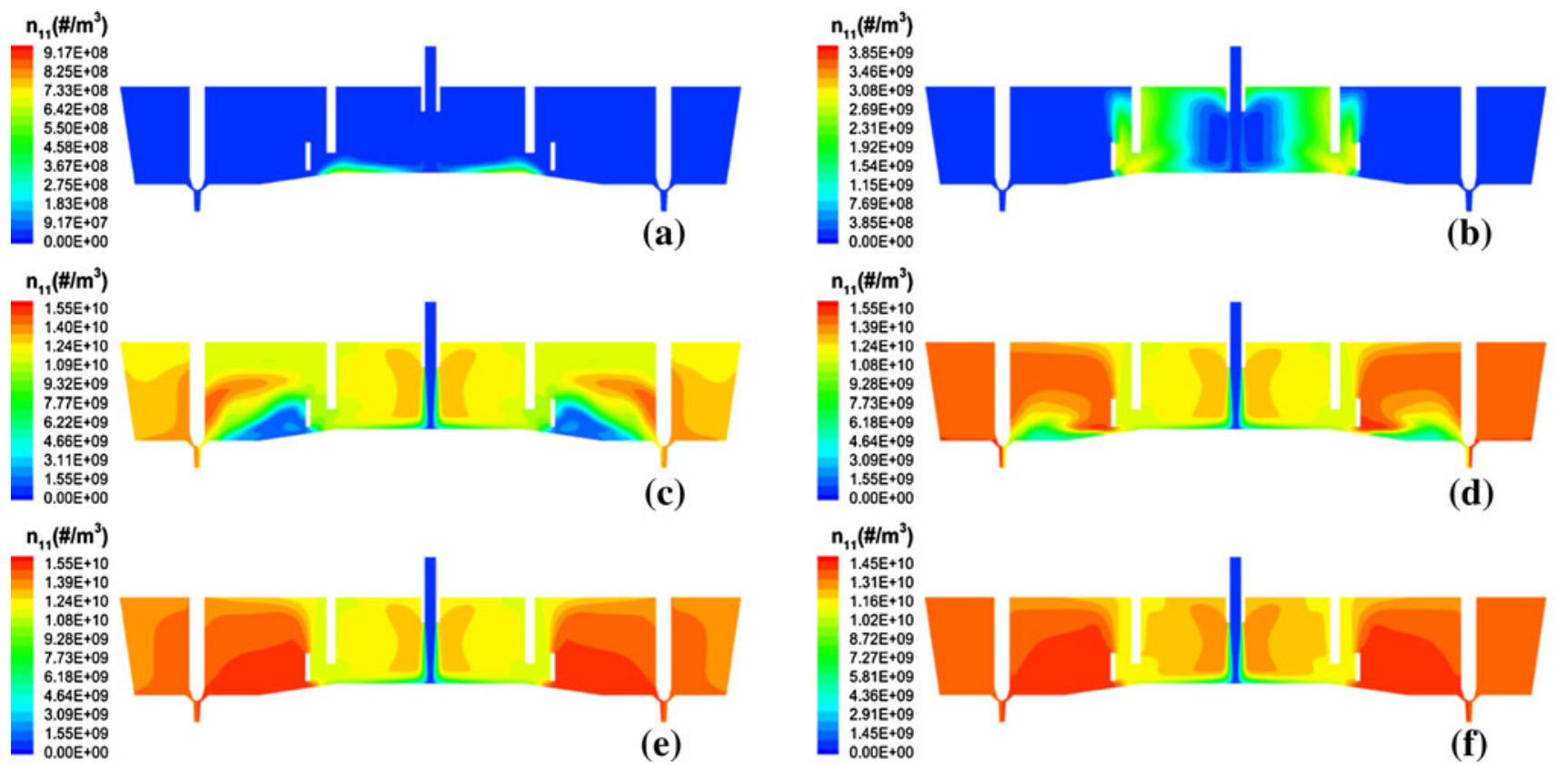

Fig. 5. The number density distribution of $8.9-\mu \mathrm{m}$ inclusions at different times: (a) $11.5 \mathrm{~s}$; (b) $31.5 \mathrm{~s}$; (c) $401.5 \mathrm{~s}$; (d) $601.5 \mathrm{~s}$; (e) $1201.5 \mathrm{~s}$; (f) $1901.5 \mathrm{~s}$.

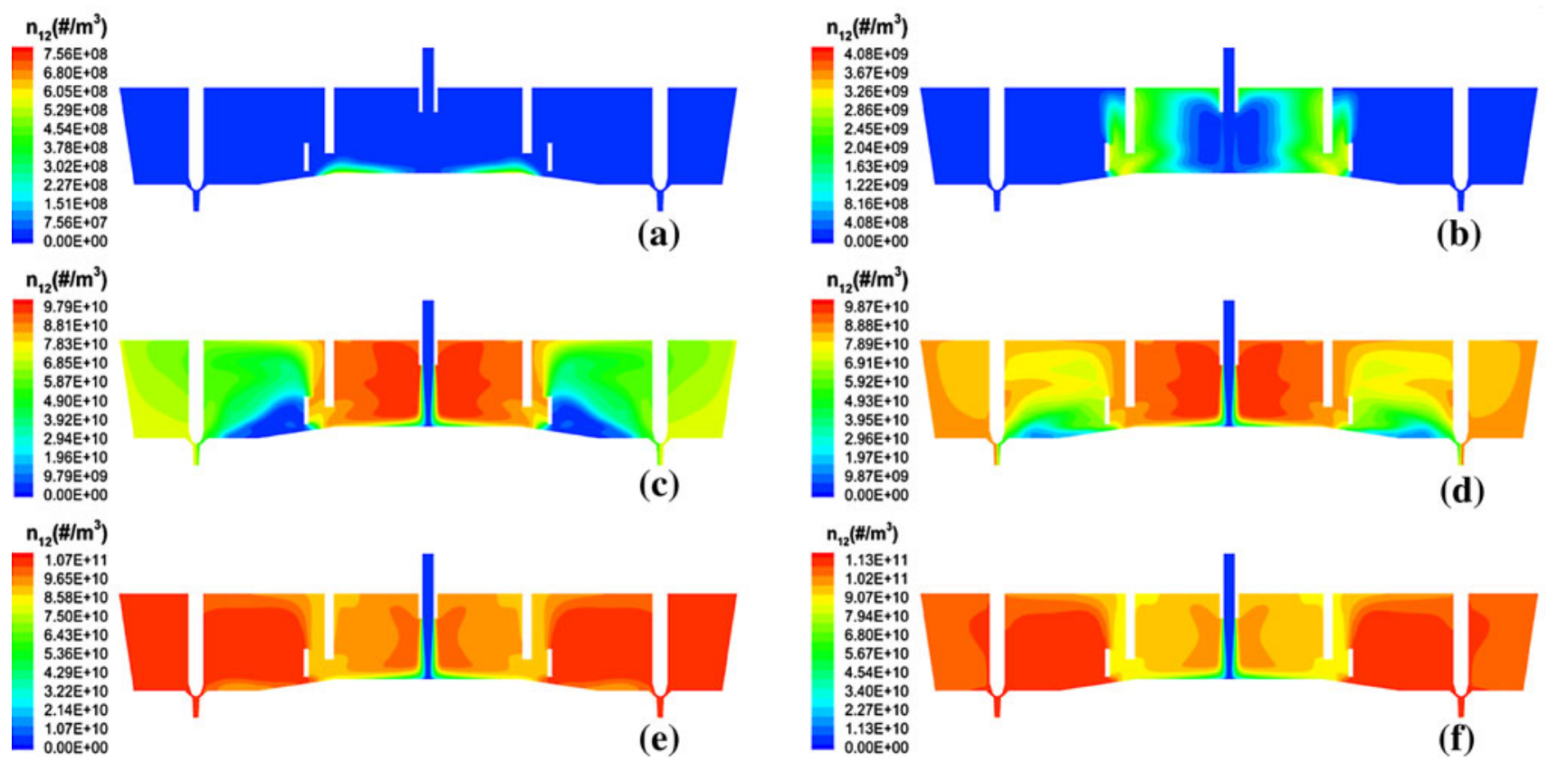

Fig. 6. The number density distribution of 9.2- $\mu \mathrm{m}$ inclusions at different times: (a) $11.5 \mathrm{~s}$; (b) $31.5 \mathrm{~s}$; (c) $401.5 \mathrm{~s}$; (d) $601.5 \mathrm{~s}$; (e) $1201.5 \mathrm{~s}$; (f) $1901.5 \mathrm{~s}$.

time at this point. This figure indicates that the number density for $4.0-\mu \mathrm{m}, 5.0-\mu \mathrm{m}$, and $9.2-\mu \mathrm{m}$ inclusions reached stable after $1000 \mathrm{~s}, 1500 \mathrm{~s}$, and $1900 \mathrm{~s}$, respectively.

Figure 8 shows that the number density of inclusions in the entire tundish changes with time. It is observed that the bigger sized inclusions were generated quickly due to collision and coalescence of the primary particles with high-collision frequency. Consequently, the number density of the primary particles decreased drastically (Fig. 8a). The number density of 5.0- $\mu \mathrm{m}$ inclusions increased markedly (Fig. 8b). The number density of the primary particles tended to be stable after $1000 \mathrm{~s}$ when the net generation rate due to inflow from the inlet, outflow from the SEN, collision, and removal from the free 
Numerical Simulation of the Growth and Removal of Inclusions in the Molten Steel of a Two-strand Tundish
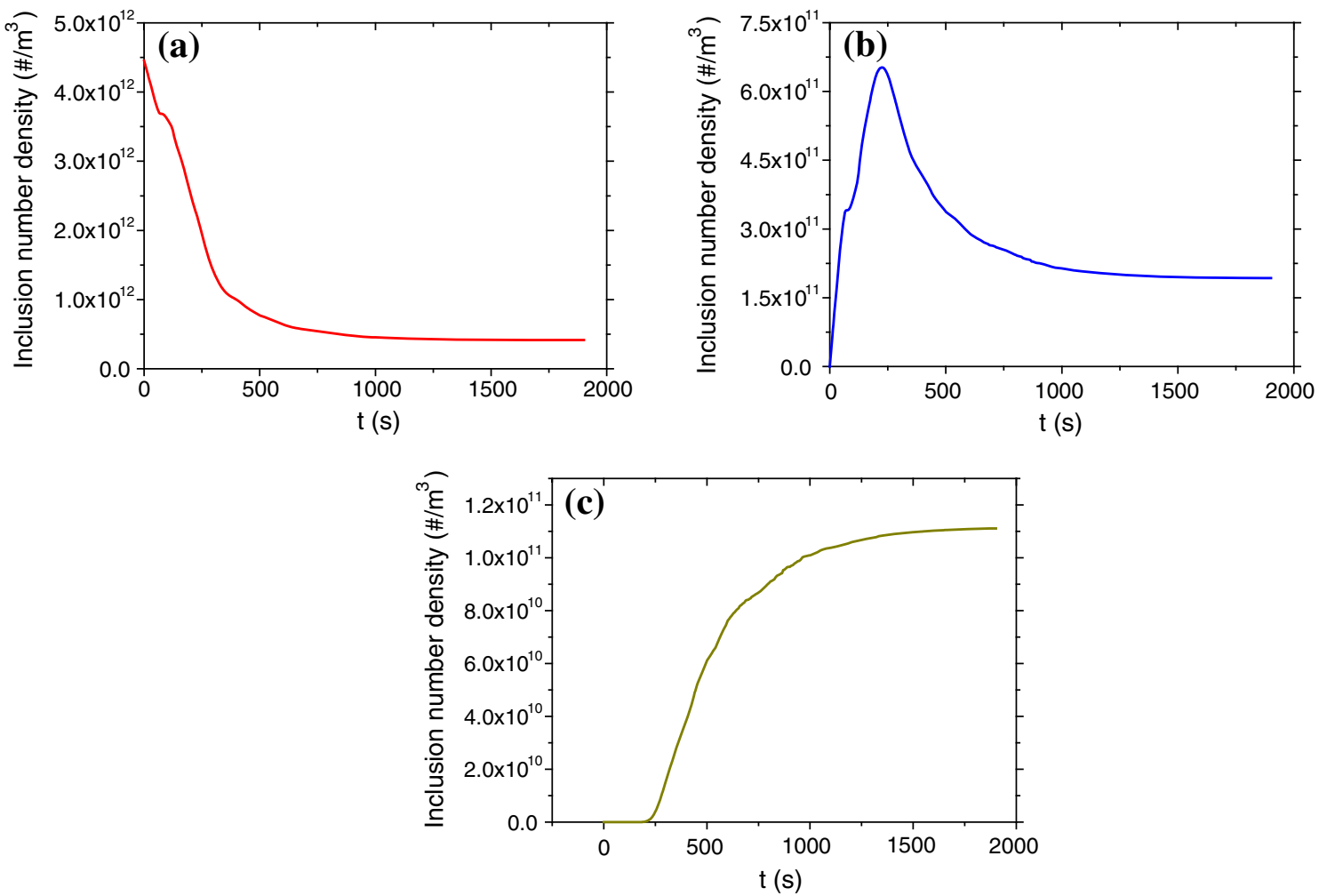

Fig. 7. Variation of the number density of different diameter inclusions with time at point $(2.0,0,0.7955):$ (a) $4.0 \mu \mathrm{m}$; (b) $5.0 \mu \mathrm{m}$; (c) $9.2 \mu \mathrm{m}$.
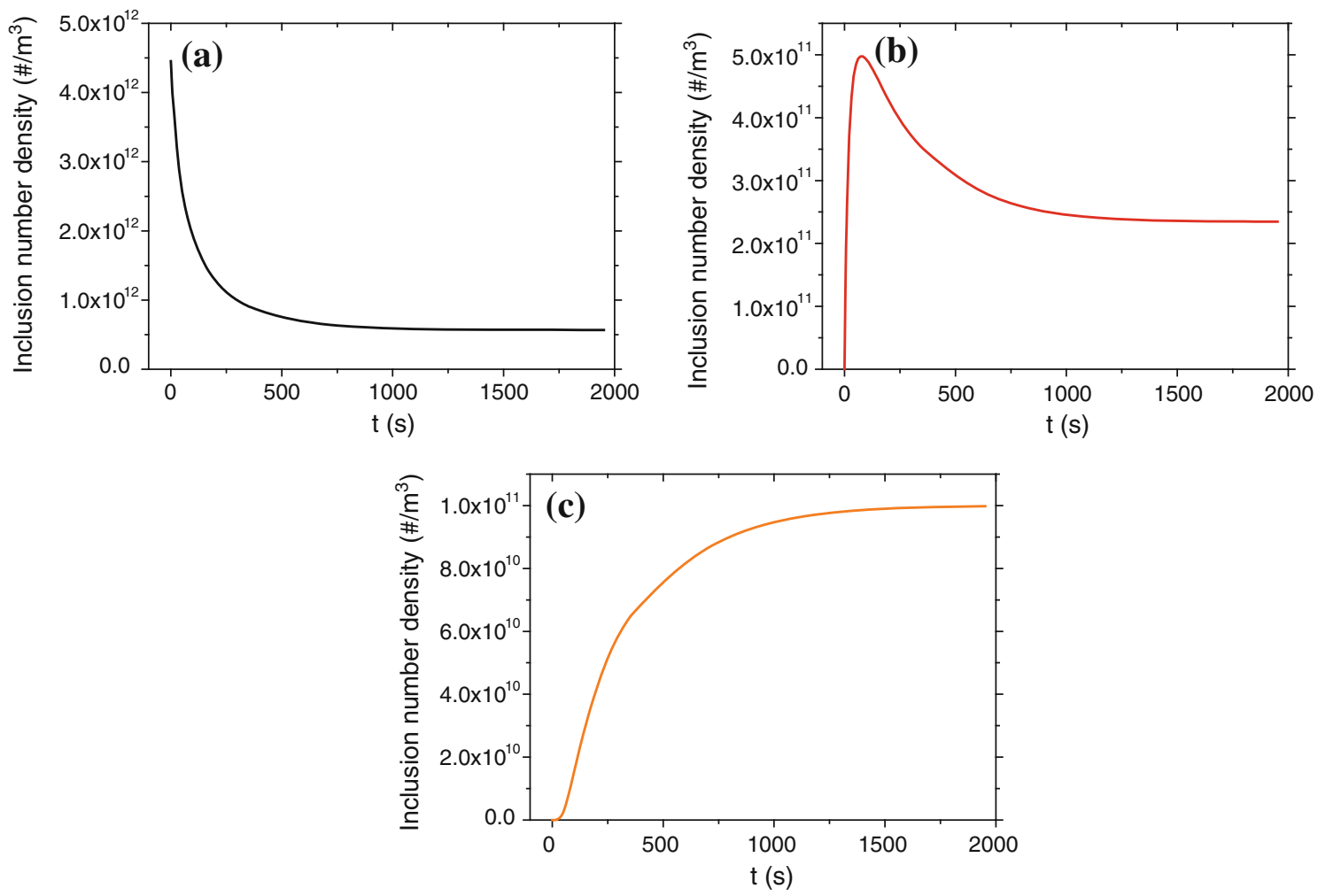

Fig. 8. Variation of the number density of different diameter inclusions in the entire tundish with time: (a) $4.0 \mu \mathrm{m}$; (b) $5.0 \mu \mathrm{m}$; (c) $9.2 \mu \mathrm{m}$. 
Table III. The concentration of different-sized inclusions at the two outlets of the tundish

\begin{tabular}{lcc}
\hline Group & $\begin{array}{c}\text { Diameter } \\
(\boldsymbol{\mu})\end{array}$ & $\begin{array}{c}\text { Concentration } \\
\text { of left and right } \\
\text { outlets }(\mathbf{p p m})\end{array}$ \\
1 & 4.0 & 9.9 \\
2 & 5.0 & 9.1 \\
3 & 5.8 & 5.3 \\
4 & 6.3 & 5.5 \\
5 & 6.8 & 3.8 \\
6 & 7.3 & 3.6 \\
7 & 7.7 & 3.0 \\
8 & 8.0 & 3.0 \\
9 & 8.3 & 2.5 \\
10 & 8.6 & 2.5 \\
11 & 8.9 & 3.5 \\
12 & 9.2 & 30.2 \\
\hline
\end{tabular}

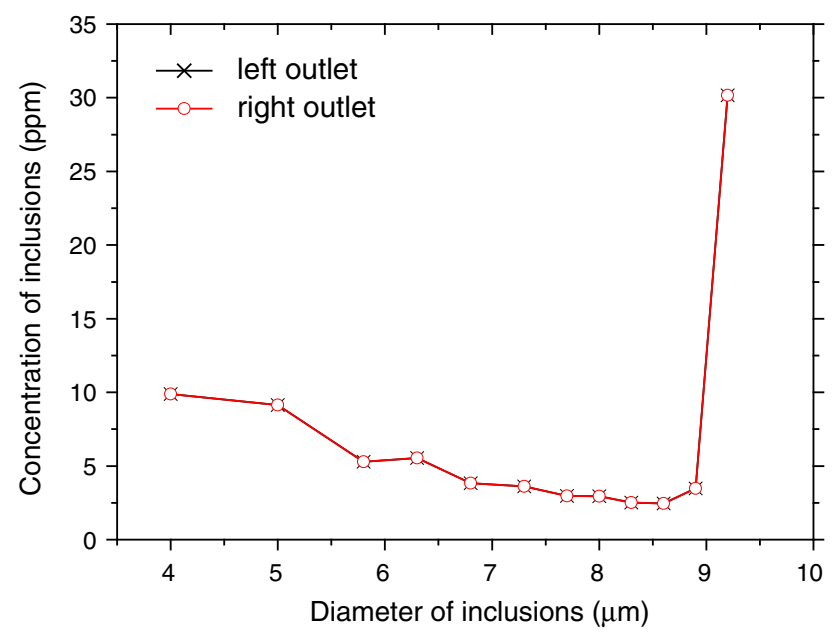

Fig. 9. The relationship between the concentration of inclusions and size at the outlet in tundish.

surface reached zero. Once the number of $5.0-\mu \mathrm{m}$ inclusions after agglomeration was less than that of $5.0-\mu \mathrm{m}$ inclusions removed, its number density decreased. Furthermore, the number density of $5.0-\mu \mathrm{m}$ inclusions increased first to a peak value, then decreased gradually, and eventually stabilized at approximately $2.347 \times 10^{11} \# / \mathrm{m}^{3}$. Figure 8c shows that the number density of $9.2-\mu \mathrm{m}$ inclusions increased all along until $1901.5 \mathrm{~s}$ to level off.

Table III and Fig. 9 show the concentration of inclusions of each size at the outlet of the tundish after reaching the steady state, which will be the initial concentration of inclusions entering the continuous casting mold. The concentration of $4-\mu \mathrm{m}$, $5-\mu \mathrm{m}$, and $9.2-\mu \mathrm{m}$ inclusions at the outlet were $9.9 \mathrm{ppm}, 9.1 \mathrm{ppm}$, and $30.2 \mathrm{ppm}$, respectively.

The concentration of other inclusions were $2.0 \mathrm{ppm}-6.0 \mathrm{ppm}$. In addition, the oxygen total content of the molten steel at the outlet is $38.5 \mathrm{ppm}$ after reaching the steady state. The contribution of turbulent collision to the removal fraction of inclusions was $23.0 \%$.

It should be noted that the strong stirring energy can be controlled within the inlet zone of the tundish using weirs and dams, providing favorable conditions for the collision and coalescence of smallsized inclusions. Moreover, the molten steel, leaving the high turbulence zone and entering the outlet zone, has a long residence time, which favors the removal of large inclusions by floating.

\section{CONCLUSIONS}

In the current study, mathematical models were developed to predict the growth and removal of inclusions in a two-strand tundish. The following conclusions were obtained:

(1) The collision and coalescence among inclusions mainly depends on the flow pattern of the molten steel. The stronger the turbulent flow is, the more beneficial to the generation of large inclusions and the faster its generation rate is.

(2) The rising velocity of $9.2-\mu \mathrm{m}$ inclusions is $1.39 \times 10^{-5} \mathrm{~m} / \mathrm{s}$, which is far smaller than the flow velocity. Small inclusions follow the fluid flow well.

(3) The strong stirring energy can be controlled within the inlet zone using the weir and dam in tundish, which provides favorable conditions for collision and coalescence of small inclusions. The molten steel flows smoothly outside the high turbulence zone and has a long residence time in the outlet zone, which helps the floating removal of large inclusions.

(4) The concentration of $4-\mu \mathrm{m}, 5-\mu \mathrm{m}$, and $9.2-\mu \mathrm{m}$ inclusions at the outlet are $9.9 \mathrm{ppm}, 9.1 \mathrm{ppm}$, and $30.2 \mathrm{ppm}$, respectively. Other groups are $2.0 \mathrm{ppm}-6.0 \mathrm{ppm}$.

(5) The oxygen total content of the molten steel at the outlet is $38.5 \mathrm{ppm}$ after reaching the steady state, and the contribution of turbulent collision to the removal fraction of inclusions was $23.0 \%$.

\section{ACKNOWLEDGEMENTS}

The research is supported by the Laboratory of Green Process Metallurgy and Modeling (GPM ${ }^{2}$ ) and High Quality Steel Consortium (HQSC) at the school of Metallurgical and Ecological Engineering at University of Science and Technology Beijing (USTB) and the National Science Foundation of China (Grant No. 51274034).

\section{REFERENCES}

1. L. Zhang and B.G. Thomas, ISIJ Int. 43, 271 (2003).

2. S. Liu, M. Liang, S. Niu, C. Li, X. Wang, and L. Zhang, Proccedings of AISTech 2006 Iron \& Steel Technology Conference and Exposition, vol.II, AIST, Warrandale, PA, May 1-4, 2006, pp. 915-927.

3. L. Zhang, J. Zhi, F. Mei, L. Zhu, X. Jiang, J. Shen, J. Cui, K. Cai, and B.G. Thomas, Ironmak. Steelmak. 33, 129 (2006).

4. L. Zhang, S. Yang, K. Cai, J. Li, X. Wan, and B.G. Thomas, Metall. Mater. Trans. B 38B, 63 (2007). 
5. S. Yang, L. Zhang, J. Li, K. Peaslee, H. Tang, and D. Wen, AISTech 2009-The Iron \& Steel Technology Conference, vol. I, AIST, Warrandale, PA, 2009, pp. 907-915.

6. S. Yang, L. Zhang, J. Li, and K.D. Peaslee, Proccedings of AISTech 2011 Iron \& Steel Technology Conference and Exposition, vol. 2, AIST, Warrandale, PA, 2011, pp. 717-729.

7. L. Sun, L. Zhang, J. Li, A. Dong, Y. Chen, and S. Yang, Iron Steel Technol. 9, 20 (2012).

8. W. Yang, X. Wang, L. Zhang, Q. Shan, and X. Liu, Steel Res. Int. 84, 2013 (in press).

9. K.-H. Tacke and J.C. Ludwig, Steel Res. 58, 262 (1987).

10. S. Chakraborty and Y. Sahai, Ironmak. Steelmak. 19, 479 (1992).

11. S. Joo and R.I.L. Guthrie, Metall. Trans. B 24, 755 (1993).

12. S. Joo, J.W. Han, and R.I.L. Guthrie, Metall. Trans. B 24, 767 (1993).

13. S. Joo, J.W. Han, and R.I.L. Guthrie, Metall. Trans. B 24, 779 (1993).

14. A.K. Sinha and Y. Sahai, ISIJ Int. 33, 556 (1993).

15. L. Zhang, S. Taniguchi, and K. Cai, Metall. Mater. Trans. B 31, 253 (2000).

16. L. Zhang, Y. Wang, D. Zhou, X. Hu, and K. Qian, Proceedings of the Third International Conference on Continuous Casting of Steel in Developing Countries (CCC'04), CSM, Beijing, China, Sep. 14-17, 2004, pp. 641-646.

17. M. Zhu, G. Wen, L. Zhang, P. Tang, Z. Su, W. Gu, K. Zhao, and G. Song, Proceedings of the Third International Conference on Continuous Casting of Steel in Developing Countries (CCC'04), CSM, Beijing, China, Sep. 14-17, 2004, pp. 214-220.

18. L. Zhang, J. Iron. Steel Res. Int. 12, 11 (2005).
19. L. Zhang, J. Zhi, J. Mou, and J. Cui, J. Iron. Steel Res. Int. 12,20 (2005).

20. L. Zhang, Transient Fluid Flow Phenomena in Continuous Casting Tundishes, Vol. 7 (Warrendale, PA: AIST, 2010), p. 15.

21. L. Zhang and S. Taniguchi, Ironmak Steelmak 28, 55 (2001).

22. L. Zhang and S. Taniguchi, Ironmak Steelmak 29, 326 (2002).

23. L. Zhang, W. Pluschkell, and B.G. Thomas, 85th Steelmaking Conference Proceedings, vol. 85, ISS, Warrandale, PA, 2002, pp. 463.

24. L. Zhang and B.G. Thomas, 7th European Electric Steelmaking Conference, (Venice, Italy), vol. 2, Milano, 2002, pp. 77.

25. L. Zhang and B.G. Thomas, Inclusion Nucleation and Growth during Steel Deoxidation, Report No. CCC200206, University of Illinois at Urbana-Champaign, 2002.

26. L. Zhang and W. Pluschkell, Ironmak. Steelmak. 30, 106 (2003).

27. P.G. Saffman and J.S. Turner, J. Fluid Mech. 1, 16 (1956).

28. K. Higashitani, R. Ogawa, G. Hosokawa, and Y. Matsuno, J. Chem. Eng. Japan 15, 299 (1982).

29. T. Nakaoka, S. Taniguchi, K. Matsumoto, and S.T. Johansen, ISIJ Int. 41, 1103 (2001).

30. S. Taniguchi, A. Kikuchi, T. Ise, and N. Shoji, ISIJ Int. 36, S117 (1996).

31. T.B. Braun, J.F. Elliott, and M.C. Flemings, Metall. Trans. B 10, 171 (1979).

32. Y. Miki, H. Kitaoka, T. Sakuraya, and T. Fujii, ISIJ Int. 32 , 142 (1992)

33. R.A. Rege, E.S. Szekeres, and W.D. Forgeng, Metall. Trans. 1, 2652 (1970). 